Fecha de recepción: abril 2020

Fecha de aceptación: mayo 2020

Versión final: junio 2020

\section{Pizzurno Pixelado: entre la \\ danza y el premapping}

Edén Bastida Kullick ${ }^{(1)}$ y Nayeli

Benhumea Salto ${ }^{(2)}$

Resumen: Existe en Argentina, una fuerte carencia de datos sobre intervenciones audiovisuales en espacios públicos que hayan utilizado la danza como elemento medular de composición. Este artículo pretende indagar particularmente en la pieza Pizzurno Pixelado de Margarita Bali, en la cuál, por medio de proyecciones de video y bailarines logra intervenir en Palacio Pizzurno.

Este trabajo indaga las posibilidades de visualizar el cuerpo dancistico a través de una proyección audiovisual, así como las deconstrucciones temporales y espaciales que se tienen al existir imagen de video y cuerpos paralelamente. Nos interesa la forma de corporeizar la imagen videográfica traduciendo los elementos formales de la danza al momento de la proyección encontrando nuevas formas de movimiento. Igualmente establecer vínculos entre la imagen videográfica y el cuerpo dancistico a través de los conceptos de falso raccord, congelamiento de imagen (la búsqueda de movimiento en el tiempo detenido), desfase o discontinuidad entre audio e imagen.

Así mismo nos preguntamos lo que puede significar una obra basada en proyecciones audiovisuales que utilizan como receptáculo la arquitectura oficial cómo en este caso el Palacio Pizzurno y lo que ahora a la distancia podríamos pensar como uno de los primeros ejercicios de mapping en la ciudad de Buenos Aires.

Palabras clave: Intervención Audiovisual - Danza - Mapping - Arte Público - Video Danza.

[Resúmenes en inglés y portugués en las páginas 254-255]

(1) Artista e investigador. Doctor en Teoría e Historia de las Artes por la Universidad de Buenos Aires (UBA). Trabaja los cruces del arte y la política, el audiovisual en múltiples formatos, las intervenciones en espacio público y la imprenta tipográfica.

(2) Artista escénica, del cuerpo, el dibujo y la poesía. Diseñadora gráfica y editorial independiente. Docente de artes, investigación y escritura para las artes. 


\section{Introducción}

Han sido muy diversas las experiencias en donde la danza se ha valido de estrategias estéticas y materiales para intervenir el espacio público. Desde mediados de los años sesenta la danza decidió salir de los espacios convencionales designados para ella. El espacio público de la ciudad, los entornos naturales y la esfera de lo privado han sido espacios invadidos de innumerables propuestas dancísticas.

Cuando pensamos la danza interviniendo el espacio público y más puntualmente en monumentos o edificios, automáticamente nos imaginamos cuerpos físicos desplazándose alrededor del espacio arquitectónico. Pero pensemos ahora en una intervención en el espacio urbano que utiliza tanto cuerpos físicos como cuerpos virtuales para interactuar momentáneamente con un palacio histórico que funciona como dependencia estatal. Y entendamos intervención como

La incorporación semántica de códigos artísticos al espacio público urbano con múltiples significados, ya sean simbólicos, identitários, políticos, territoriales, lúdicos o irreverentes, que por lo general asumen un carácter efímero. Mediante lenguajes y discursos artísticos opera la resignificación estética y cultural del espacio público (Sánchez, 2003, p. 9).

En el año 2005, Margarita Bali realizó una video-instalación sobre la fachada del Palacio Pizzurno en la ciudad de Buenos Aires, el cuál opera actualmente como sede del Ministerio de Educación de la Nación. La pieza integraba la danza y la música en vivo con el video y la proyección de imágenes y animaciones pregrabadas. Esta obra fue realizada como parte del proyecto CRUCE dentro del Festival Internacional de Teatro FIBA 2005. Precisamente, dado el fuerte apoyo institucional, la pieza contaba con la más alta tecnología de aquel momento, la cual estaba integrada por un gran proyector frontal de alto alcance y tres proyectores emplazados desde el interior del palacio.

Margarita Bali ya había experimentado con el lenguaje del video en sus variadas formas; tanto en simultáneo a la escena en vivo en las obras: Dos en la Cornisa, Ave de Ciudad Naufragio in Vitro, así como en el ámbito de las video-instalaciones en galerías y museos con las piezas La Raja, Pulmotor, La Isla Pirámide y Pirámide Arena. En este afán de experimentación con el soporte de video, Bali decide lanzarse al espacio público de manera material. Sin embargo, la noción de espacio público ya estaba presente en sus anteriores trabajos de videodanza, aunque esta obra representa un primer intento de apropiación simbólica de los elementos urbanos.

\section{Cuerpo/video}

El cuerpo y su relación con el video puede alcanzar un sinfín de formas de transformación y manipulación. Al mismo tiempo, su relación ha permitido un entendimiento diferente de la danza escénica; por ejemplo: la posibilidad de pensar el cuerpo como una figura 
digitalizada implica pensarlo con características propias de lo visual antes que de lo coreográfico.

En la pantalla el cuerpo del bailarín, si bien es la fuente originaria de la imagen, ya no es el medio a través del cual se plasma la idea coreográfica, ahora el medio es un soporte material diferente del cuerpo, que contiene datos de esa nueva corporalidad (Lachino/Benhumea, 2010, p. 54).

En este sentido, el cuerpo encuentra reinterpretaciones de sí mismo a partir de su forma digital que poco tiene que ver con el cuerpo escénico, pues mediante los procesos de captura y edición de video es posible manipular su forma, su movimiento, tiempo y espacio, pudiéndolo distorsionar, procesar, etc.; el cuerpo se convierte en imagen, en un gráfico que se compone por códigos binarios y/o por pixelación, pero cuyo origen es la representación de un cuerpo real en acción y en movimiento; se desprende de los aspectos de la física y recrea sus propios aspectos corporales, intensificando su potencia, su velocidad, su resolución, su cadencia, incluso sus posibilidades de crear otros movimientos. Podemos decir entonces que las tecnologías generan otras visiones del ser, otras formas de ver el cuerpo y la oportunidad de construir diferentes corporalidades. Cada artista construirá su propio cuerpo con sus necesidades estéticas, tecnológicas y artísticas.

En el caso de esta video-intervención, se conjugan tanto cuerpos físicos en estrecha relación con cuerpos virtuales, en permanente búsqueda de diálogo e interacción entre ellos. Pero la transformación de los cuerpos, tanto físicos como virtuales relacionados con una intervención urbana en la práctica de la danza, modifica en gran medida el quehacer cotidiano de las prácticas coreográficas. En este caso, la danza ya no solo trata de salir al espacio público y vincular cuerpo con ciudad, ahora el elemento videográfico a la ahora de intervenir la ciudad, se integra como un tercer elemento que está cargado de simbolismos y mecanismos de funcionamiento diferentes, que le otorgan una estructuración multidisciplinaria a la propia danza. Por lo tanto, la búsqueda entre estos tres medios: danza, video y arquitectura, se centra en lograr una vinculación total de los diversos cuerpos con el palacio.

Bachelard (1994) propone dos imágenes también muy sugerentes para pensar la imagen interactiva entre individuo y arquitectura; se trata de la evolución conjunta entre espacio vital y el cuerpo que lo habita, que puede resultar en dos tipos de transformaciones: una primera imagen representa la creación del espacio a la medida del cuerpo que lo habita (molusco): no se edifica la casa para vivir en ella, sino que al vivir se va conformando el espacio. Una casa que crece en la medida misma en la que crece el cuerpo que vive en ella. La segunda imagen es la del cuerpo que se adapta y se conforma adecuándose al espacio que habita, la de Quasimodo, para quien la catedral de Notre Dame había sido el huevo, el nido, la casa, la patria, el universo.

Partimos de que el cuerpo es material digital dado que ocupa un espacio en la máquina, pero también es virtual pues ésta digitalización lo descarna de su modo físico. El cuerpo como imagen no se basa en un modelo real, puede ser una imagen sin "referente", es decir, vale por sí misma. En Pizzurno Pixelado como ya mencionamos existen múltiples cuerpos. Pero en este caso lo interesante a la hora de intervenir es el cuerpo digitalizado, el cuál 
modifica nuestra concepción individual de cuerpo, exteriorizándolo en forma de imagen electrónica (video). Un cuerpo que se entrelaza entre la realidad física y la virtualidad. Ahora, los desarrollos de la danza y el cuerpo en movimiento, nos llevan a reconocer un nuevo tipo de experiencia donde "ya no se trata simplemente de contemplar a distancia y frontalmente, la imagen de algo, sino de introducirse en los intersticios de una realidad compuesta, mitad imagen, mitad sustancia". Así como "el cuerpo biológico incorpora transformaciones por la presencia de cuerpos mecánicos, ahora existe otro cuerpo informático que modifica nuestra concepción individual de cuerpo" (Quéau, 1993, p. 18).

\section{Coreografía para proyectarse en monumentos}

La presencia de los medios electrónicos y tecnológicos en las artes escénicas, en especial en la danza, han delineado un nuevo camino que nos interesa explorar, la experimentación coreográfica. El uso del video ha otorgado a la danza un entendimiento de ella misma diferente a las concepciones tradicionales. Por tanto, nos interesa poner especial énfasis en la manera de construir coreografía pensando en el diálogo que ésta tendrá con el video y con el edificio -receptáculo de proyección-. Esto nos lleva a trasladar lo meramente escénico y "puro" a una construcción danza-tecnología en la que la danza sale de su acostumbrada posición creativa para entrar en discursos múltiples, es decir, pensar la danza en relación con la imagen electrónica y la arquitectura. Esto sin duda produce una percepción totalmente diferente e intensificada en los espectadores.

Desde el momento en que la danza contemporánea salió tanto de los teatros como de los estudios para insertarse en la cotideanidad de la calle, se ha optado por el empleo de diferentes materiales de movimiento, se han desarrollado nuevas metodologías de composición y se han concebido otras formas de posibilitar la experiencia estética mediante la coreográfia.

La danza es capaz de dar una nueva lectura a los espacios. Un buen trabajo coreográfico explora las dimensiones narrativas y dramáticas de los mismos. Detecta algunas cualidades ocultas funcionales y simbólicas de los espacios urbanos. Puede dar una visión dramática, poética o, simplemente, -¿por qué no?- geométrica (Mira, 2006, p. 22).

La importancia que destacamos al generar una obra de danza para un espacio como el Palacio Pizzurno, es el hecho de permitir al coreógrafo, en este caso la propia Margarita Bali y evidentemente a todos los bailarines participantes, pensar su movimiento y sus acciones para un espacio ajeno al ocupado a la hora del montaje. Trasladar esa concepción de las cualidades físicas y traducirla pensando en otro espacio, nos parece de gran importancia para las nociones tradicionales de la danza, principalmente la del teatro a la italiana. En este caso, el impulso coreográfico parte de la exploración cinética de una arquitectura, en la que el Bali encuentra estímulos espaciales para desarrollar su discurso. Ésta idea, nos lleva a pensar puntualmente en los ámbitos formales de la realización de la pieza en cuanto 
a lo coreográfico -y decimos en este caso pieza y no intervención, ya que hablaremos de la cuestión previa de maquetación coreográfica de la obra y no el momento de proyección en sí-, es decir de la cuestión del registro videográfico de la danza en función de la proyección. En este sentido la coreografía a nivel de gestación no tiene nada que ver con el espacio escénico. El registro de los bailarines en gran medida está realizado con planos cenitales, por lo tanto las acciones a registrar suceden en el piso, dando la impresión de estar de pie o "volando" una vez que se proyecta en el palacio. A su vez, la intervención en vivo nos da la sensación de una integración material del cuerpo de los bailarines videograbados y el palacio. Como ejemplo claro de ello reconocemos el inicio de la intervención, en donde vemos a un bailarín escalando un edificio. Una ilusión en la mente del espectador que fue determinada desde la realización de la obra.

Las posibilidades estéticas del cuerpo están delimitadas por las características tecnológicas tanto de la cámara como de los sistemas de edición y postproducción. En Pizzurno Pixelado, la coreografía fue grabada en una temporalidad específica, en la que los bailarines realizan sus acciones de principio a fin, con cortes en las tomas seguramente, pero en una sola temporalidad que fue la sucedida en la grabación. Posteriormente, con el uso de la edición y postproducción, es evidente que esa temporalidad genera modificaciones que tienden a acelerar el movimiento, repetirlo, desacelerarlo; en la construcción de una coreografía para la escena, el ritmo juega de manera distinta, los caminos temporales y espaciales se construyen en función de las propias posibilidades físicas; sin embargo, podemos ver cómo en el video, el espacio y el tiempo se manipulan también en pro y muchas veces en contra de la obra.

Otro aspecto importante es que el video, además de las características ya descritas, le otorga a la danza un campo infinito de multiplicidades corporales. Como una hipótesis emanada de una primera revisión de la obra Pizzurno Pixelado, es posible plantear que los cuerpos proyectados pudieran ser dos, ofreciendo la posibilidad en la postproducción de repetirlos y multiplicarlos de manera infinita, agregando con ello una ilusión más en el espectador.

La edición de video es entonces, en comparación con la danza, una forma de construir coreografía. No sólo aparece aquí la proyección de una coreografía concebida para ser grabada de una forma y proyectada en un espacio específico, sino además surge la posibilidad de construir una coreografía paralela o terminar de concebir la coreografía, si así se quiere, en los procesos de edición.

\section{Una experiencia cinematográfica tradicional}

Muy diversas miradas podrían situar la pieza antes mencionada como una propuesta del llamado Cine Expandido, terminología acuñada por Gene Youngblood a finales de los años sesenta. Sin embargo, no estamos totalmente de acuerdo en ello, ya que Pizzurno Pixelado repite una experiencia cinematográfica tradicional en muchos sentidos. No se concreta en uno de los puntos mas importantes de los que pregonaba Youngblood, que es la estimulación de la corporalidad de los espectadores, es decir el carácter sinestésico de la 
pieza, la capacidad de capturar sensorialmente al público, intentando que este encuentre estados alterados de conciencia al vivenciar el flujo audiovisual en una proyección. Es en este punto donde nos preguntamos: ¿es posible que en una video-instalación monumental como está se pueda lograr la estimulación sensorial de los espectadores, o se queda en todos los casos en un espectáculo monumental? Consideramos que no es suficiente que el video abarque grandes dimensiones y se entrelace con el palacio para que exista una captura sensorial del público, por el contrario creemos que las grandes dimensiones de las proyecciones solo hacen cuestionar en el espectador nociones técnicas de la misma, más aún cuando se trata de la primera pieza de estas características en Argentina. Es por esto que repite una experiencia cinematográfica tradicional, aunque obviamente a gran escala. Pensar la relación de danza y experiencia cinematográfica tradicional nos lleva automáticamente a La Danza de la Serpentina ${ }^{1}$, espectáculo pre-cinematográfico que realizaban los hermanos Skladanowsky en Alemania, con su Bioskop; el cuál consistía en un proyector de cine que desarrollaron con pocos medios, meses antes de que tuviera lugar la primera exhibición comercial del cinématographe de los hermanos Lumiére en el Salón Indiano del Gran Café de París, el 28 de Diciembre de 1895. En este caso al igual que en Pizzurno Pixelado se repiten dos elementos claves del ritual cinematográfico. Por un lado existe una clara visualización frontal por parte de los espectadores, la atención en todo momento está puesta frente a nosotros y la mirada no se puede retirar de ese punto, estamos cautivos por el flujo audiovisual. Y por otro, la existencia de una convocatoria para asistir, un horario fijo tanto de inicio como de terminación de la pieza visual.

Otro punto, es la cuestión de la existencia de una sola pantalla totalmente delimitada. El palacio se convierte en una gran pantalla rectangular compuesta de tres pisos de siete ventanas por piso, es decir veintiún ventanas en total a disposición del flujo visual. Pero al fin y al cabo una gran pantalla. Esto ocurre en oposición al interés que tenía el Cine Expandido, el cuál buscaba la multiplicidad de pantallas y experimentar con las más diversas formas de visualización de la materia audiovisual. Existen por último, dos elementos formales en la pieza que ayudan a afianzar nuestra idea de que Pizzurno Pixelado se convierte en una experiencia cinematográfica tradicional; 1 . La idea de poner el título al inicio de las proyecciones y 2. Finalizar con los créditos del equipo de producción que participó en la obra, al más puro estilo cinematográfico.

\section{Video-instalación como escultura monumental}

Jean Paul Fargier (1986) hablaba ya de la video-instalación como forma moderna de escultura. Esto nos lleva a pensar Pizzurno Pixelado como una clara puesta en abismo, es decir, elaborar un concepto sobre ese mismo concepto. Existe una escultura -la videoinstalación-sobre otra escultura -el Palacio Pizzurno-. Para atrevernos a decir esto, no partímos de la idea elástica o heterogénea de campo expandido de la escultura propia del posmodernismo. Llegamos a esta conclusión pensando en la lógica de la escultura como inseparable a la lógica del monumento, es decir, como una representación conmemorativa 
y en ambos casos -palacio y video-instalación- se gestan por encargo conmemorando eventos puntuales. Por lo tanto las englobaremos como monumentos.

Consideramos que esta idea de hablar de Pizzurno Pixelado como monumento escultórico se refuerza al hablar del uso del lugar o emplazamiento en la escultura. Esta pieza no puede ser llevado a cabo en otro edificio, como escultura funciona justo en otra escultura llamada Palacio Pizzurno. Esto nos lleva a pensar, por obvias razones, en que es una pieza de especificidad espacial, que nos remite al famosísimo anglicismo site specific. Aún y cuando lo hemos enmarcado como una pieza escultórica; no queremos dejar de mencionar que la presente video-instalación marca la superación definitiva de la noción de espacio escultórico nacida en el Renacimiento y la instauración de un espacio dialógico y vivencial dependiente de la experiencia del espectador.

Es claramente conocido el poder de la arquitectura como vehículo ideológico. El Palacio ha variado infinidad de veces en cuanto al uso que se le da, desde escuela de señoritas, hasta diversos ministerios gubernamentales, es por eso que el peso ideológico se limita a pensarlo como espacio estatal, no mas allá de eso. Por lo tanto consideramos que no existe relación ideológica directa entre la imagen del video y el palacio. Y cómo va a existir, si su peso ideológico estatal en nada tiene que ver como los cuerpos danzando sobre él de manera física y virtual. El Palacio en los cuarenta minutos de duración de la obra se limita a recibir flujos audiovisuales e intentar ser o significar otra cosa. Es un pedido de ser habitado. En este caso por bailarines, naturaleza y luz.

Un punto trascendental en relación a lo anterior, y que se convierte en parte fundamental de diversas obras artísticas que utilizan la arquitectura como punto de intervención, es la idea de pensar el Palacio Pizzurno a través de una memoria alienigena ${ }^{2}$. Es decir, que el palacio tenga una oportunidad de disculparse y aunque sea por un pequeño rato no tener el rol que normalmente le imponemos: abstraer por cuarenta minutos al Palacio de representar la misma narrativa de siempre, la de todos los días. Con las proyecciones de video, los edificios tienen la oportunidad de pretender que no son lo que realmente no son. De este modo el palacio se transforma en espacio vivido y transformado, manipulado por la imaginación.

Desde hace algunos años el Estado, presionado por diversos grupos de ciudadanos, ha incentivado un tipo de arte público, aun cuando éste tipo de arte es utilizado solamente con la idea de impresionar, decorar o adornar. El Estado ahora varía su carácter de promotor de arte monumental, ese arte público al que le interesan ya las "obras de arte estatal" no se centran en la visibilidad de nuestro pasado como nación (próceres y acontecimientos históricos), aunque se sigue poniendo el foco en los grandes espacios públicos. Sin embargo, su objetivo no se altera y se sigue cumpliendo; reunir al público alrededor de una pieza de arte, anteriormente esculturas gigantes, ahora proyecciones de video monumentales. A este arte monumental, el Estado lo llama arte público. Para esto es importante pensar que "el concepto y la práctica del public art proviene de Estados Unidos que ha extendido al mundo civilizado ese modelo urbano en correspondencia al dominio económico y político de las empresas multinacionales" (Duque, 2002, p. 114). El arte publico estatal que ha inundado recientemente nuestras plazas es el mejor ejemplo de cómo se cosifica y tipifica la particularidad local como espectáculo. Igualmente el factor tecnológico juega otro papel importante, la tecnología y los modos de capitalismo avanzado imponen una 
resignificación y redistribución del valor de espacio tan drástica como las que se supuso la formación del estado moderno.

\section{Conclusión}

En Pizzurno Pixelado se advierte una conjunción entre la realidad física en la que estamos inmersos, al mismo tiempo que aparecen elementos virtuales mostrados en un espacio no-escénico. Por lo tanto se convierte en una posibilidad más de experiencias multimedia en el ámbito de la danza. Consideramos que el logro mayor de la pieza es que se permite poner al cuerpo en correspondencia con el espacio, el lugar y el acontecimiento, sea éste físico real o virtual y aumentado, pero siempre como cuerpo que siente y se experimenta no solo en la percepción externa.

Es importante reconocer la obra como la primera video-instalación a gran escala sobre una fachada arquitectónica fomentada desde los aparatos oficiales de cultura en Buenos Aires. Obviamente, qué mejor que fuera en un palacio de control estatal como el Pizzurno. Es por esto que la podemos llamar entonces como la primera gran obra estatal que mezcla video, danza y música. De igual manera consideramos -dadas sus características formalesque esta pieza viene a ser el primer ejercicio de mapping ${ }^{3}$ que se realizó en la ciudad de Buenos Aires, como señala la misma Bali,

...me inventé el mapping, ya que en ese entonces no se hablaba de mapping. Grabe, tomé fotos del edificio, recorte, puse blanco y negro las ventanas, empecé a trabajar con los bailarines y las imágenes que se proyectarían. Hice una maqueta del edificio de tal manera que los bailarines podían trabajar detrás de la maqueta ${ }^{4}$.

Está técnica que cinco años mas tarde, en plenos festejos del Bicentenario de Independencia fuera masificada y altamente utilizada como forma de espectáculo tanto por el gobierno de la nación, con el mapping sobre el Cabildo, como el gobierno de la ciudad de Buenos Aires y su mapping sobre el Teatro Colón, tal como ha ocurrido en otras ciudades de Latinoamérica, como en el Zócalo de la ciudad de México para los propios festejos del Bicentenario de la Independencia, en septiembre de 2010.

\section{Notas}

1. Idea que retomaría mas tarde Lois Fuller, y que para muchos es considerado en primer ejercicio de danza en pantalla.

2. Entrevista titulada "Vigilar a los vigilantes: De la energía del disimulo al proyector más caro del mundo". Realizada por Fernando Llanos a Rafael Lozano-Hemmer en 2003. http://www.fllanos.com/entrevistas/lozano-hemmer.html 
3. Mapping: técnica de gráficos computacionales consistente dar un aspecto rugoso a las superficies de los objetos. Esta técnica modifica las normales de la superficie sin cambiar su geometría

4. Entrevista realizada por el autor del presente ensayo y Carolina Arandia a Margarita Bali en 2013 http://cuadernosdedanza.com.ar/textosdanzacontemporanea/70/entrevista margaritabali

\section{Bibliografía}

AA.VV, (2006). Ciudades que danzan. Danza en paisajes urbanos. Barcelona: Associació Marató de l'Espectacle.

Alonso, R. (2004). “El espacio expandido". en art.es, año 6, no 7.

Auge, M. (2004). Los no lugares. Una antropología de la sobremodernidad. Barcelona: Gedisa. Bachelard, G. (1994). La poética del espacio. Madrid: Fondo de Cultura Económica.

Benhumea, N. y Lachino, H. (2010). Videodanza, de la escena a la pantalla. Universidad Nacional Autónoma de México-Coordinación de Danza. México. http://www.danzay tecnologia.org/

Blanco, P.; Carrillo, J.; Claramonte, J. y Exposito, M. (eds) (2001). Modos de hacer. Arte crítico, esfera pública y acción directa. Salamanca: Ediciones Universidad de Salamanca.

Ceriani, A. (2012). "Investigación en la interacción entre un escenario laboratorio y un cuerpo extendido" en Jornadas de Sociología de la Universidad Nacional de La Plata "Argentina en el escenario latinoamericano actual: debates desde las ciencias sociales".

Duque, F. (2002). Arte Publico y Espacio Político. Madrid: Akal.

Fargier, J.P. (1986). "Les electrons ont la vie duré”. En Oú va la vidéo? París: Cahiers du Cinema.

Kerkhove, D. (1999). La piel de la cultura. Barcelona: Gedisa.

Krieger, P. (2006). Megalópolis: La Modernización de la Cuidad de México. México: Universidad Nacional Autónoma de México.

La Ferla, J. (1996). La revolución del video. Buenos Aires: Libros del Rojas, Eudeba. . (1997). Contaminaciones. Del videoarte al multimedia. Buenos Aires: Libros del Rojas, Eudeba.

. (2009). "Teatros virtuales inmersitos interactivos: La ópera del mundo", en Cine (y) digital, Aproximaciones a posibles convergencias entre el cinematógrafo y la computadora. Buenos Aires: Ediciones Manantial SRL.

Quéau, P. (1993). Lo virtual. Virtudes y vértigos. Buenos Aires: Paidos.

Sánchez, A. B. (2003). La intervención artística de la ciudad de México. México: Consejo Nacional para la Cultura y las Artes.

Youngblood, G. (2012). Cine Expandido. 1a edición, Saenz Peña: Universidad Nacional Tres de Febrero. 


\author{
Sitios web \\ http://www.margaritabali.com \\ http://www.youtube.com/watch?v=mtNPFopX6WM \\ http://www.youtube.com/watch?v=JN02XYDyyk4 \\ http://www.youtube.com/watch?v=-zA5k6JNhPs \\ http://www.youtube.com/watch?v=ENyOj26hmH0
}

\begin{abstract}
In Argentina, there is a strong lack of data on audiovisual interventions in public spaces that have used dance as a core element of composition. This article aims to investigate particularly in the piece Pizzurno Pixelado by Margarita Bali, in which, through video projections and dancers, she manages to intervene in the Pizzurno Palace.

This work investigates the possibilities of visualizing the dancing body through an audiovisual projection, as well as the temporal and spatial deconstructions that exist when video images and bodies exist in parallel. We are interested in the way of embodying the videographic image by translating the formal elements of dance at the moment of projection, finding new forms of movement. Likewise, establish links between the videographic image and the dancing body through the concepts of false raccord, image freezing (the search for movement in stopped time), lag or discontinuity between audio and image.

Likewise, we wonder what a work based on audiovisual projections that use official architecture as a receptacle can mean, such as in this case the Pizzurno Palace and what now, at a distance, we could think of as one of the first mapping exercises in the city of Buenos Aires.
\end{abstract}

Keywords: Audiovisual Intervention - Dance - Mapping - Public Art - Video Dance.

Resumo: Na Argentina, há uma forte falta de dados sobre intervenções audiovisuais em espaços públicos que utilizaram a dança como elemento central da composição. Este artigo pretende investigar particularmente a peça Pizzurno Pixelado de Margarita Bali, na qual, através de projeções de vídeo e dançarinos, ela consegue intervir no Palácio Pizzurno. Este trabalho investiga as possibilidades de visualização do corpo do bailarino através de uma projeção audiovisual, assim como as desconstruções temporais e espaciais que existem quando imagens de vídeo e corpos existem em paralelo. Estamos interessados na forma de encarnar a imagem de vídeo, traduzindo os elementos formais da dança no momento da projeção, encontrando novas formas de movimento. Da mesma forma, estabelecer vínculos entre a imagem de vídeo e o corpo de dança através dos conceitos de falso raccord, congelamento de imagem (a busca do movimento no tempo parado), atraso ou descontinuidade entre o áudio e a imagem.

Também nos perguntamos o que um trabalho baseado em projeções audiovisuais que usam a arquitetura oficial como receptáculo, como o Palácio Pizzurno, poderia significar 
e o que poderíamos pensar agora como um dos primeiros exercícios de mapeamento na cidade de Buenos Aires.

Palavras chave: Intervenção Audiovisual - Dança - Mapeamento - Arte Pública - Dança em Vídeo.

[Las traducciones de los abstracts fueron supervisadas por el autor de cada artículo] 